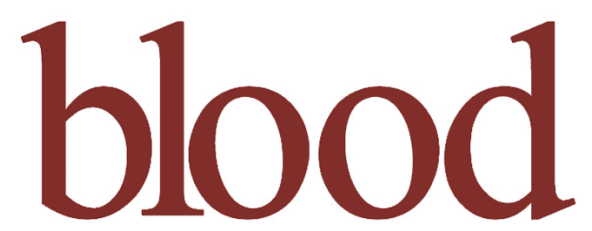

2011 118: 5458-5465

Prepublished online September 14, 2011; doi:10.1182/blood-2011-04-351460

\title{
A zebrafish model of dyskeratosis congenita reveals hematopoietic stem cell formation failure resulting from ribosomal protein-mediated p53 stabilization
}

Tamara C. Pereboom, Linda J. van Weele, Albert Bondt and Alyson W. MacInnes

Updated information and services can be found at:

http://bloodjournal.hematologylibrary.org/content/118/20/5458.full.html

Articles on similar topics can be found in the following Blood collections

Hematopoiesis and Stem Cells (2940 articles)

Information about reproducing this article in parts or in its entirety may be found online at:

http://bloodjournal.hematologylibrary.org/site/misc/rights.xhtml\#repub_requests

Information about ordering reprints may be found online at:

http://bloodjournal.hematologylibrary.org/site/misc/rights.xhtml\#reprints

Information about subscriptions and ASH membership may be found online at: http://bloodjournal.hematologylibrary.org/site/subscriptions/index.xhtml

Blood (print ISSN 0006-4971, online ISSN 1528-0020), is published weekly by the American Society of Hematology, 2021 L St, NW, Suite 900,

Washington DC 20036.

Copyright 2011 by The American Society of Hematology; all rights reserved.

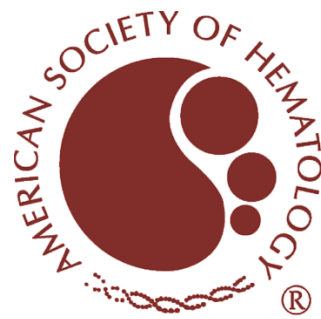




\title{
A zebrafish model of dyskeratosis congenita reveals hematopoietic stem cell formation failure resulting from ribosomal protein-mediated p53 stabilization
}

\author{
*Tamara C. Pereboom, ${ }^{1}{ }^{*}$ Linda J. van Weele, ${ }^{1}$ Albert Bondt, ${ }^{1}$ and Alyson W. Maclnnes ${ }^{1}$ \\ ${ }^{1}$ Hubrecht Institute, Koninklijke Nederlandse Akademie van Wetenschappen and Universitair Medisch Centrum Utrecht, Utrecht, The Netherlands
}

\begin{abstract}
Dyskeratosis congenita (DC) is a bone marrow failure disorder characterized by shortened telomeres, defective stem cell maintenance, and highly heterogeneous phenotypes affecting predominantly tissues that require high rates of turnover. Here we present a mutant zebrafish line with decreased expression of nop10, one of the known H/ACA RNP complex genes with mutations linked to DC. We demon-
\end{abstract}

strate that this nop10 loss results in 18S rRNA processing defects and collapse of the small ribosomal subunit, coupled to stabilization of the p53 tumor suppressor protein through small ribosomal proteins binding to Mdm2. These mutants also display a hematopoietic stem cell deficiency that is reversible on loss of p53 function. However, we detect no changes in telomere length in nop10 mutants. Our data support a model of DC whereupon in early development mutations involved in the H/ACA complex contribute to bone marrow failure through p53 deregulation and loss of initial stem cell numbers while their role in telomere maintenance does not contribute to DC until later in life. (Blood. 2011;118(20): 5458-5465)

\section{Introduction}

Dyskeratosis congenita (DC) is a congenital disease that in one comprehensive population-based study was found to represent up to $5 \%$ of all bone marrow failure disorders. ${ }^{1}$ Patients with this disease typically present in the first decade of life with a classic triad of phenotypes, including nail dystrophy, oral leukopathies, and hyperpigmentation of the skin. ${ }^{2}$ More than $90 \%$ of all DC patients will experience cytopenia before the age of $20 .^{3}$ Other phenotypes reminiscent of aging may develop later in life, including premature graying of the hair, alopecia, taurodant teeth, and osteoporosis. ${ }^{4-6}$ Although the majority of DC patients die from bone marrow failure, an increased risk of malignancy also contributes to DC mortality. ${ }^{7}$

The genotypes of DC vary as widely as the phenotypes and encompass genes that are, with one exception, involved in the H/ACA RNP complex and/or telomere maintenance. Dyskerin $(D K C 1)$ was the first H/ACA complex gene linked to DC, the $\mathrm{X}$-linked form of which has been implicated in the more severe cases of DC. ${ }^{8} \mathrm{DKCl}$ mutations have also been linked to HoyeraalHreidarsson syndrome, ${ }^{9}$ which is now considered to be an extreme form of DC with an earlier onset and a shorter life expectancy. Mutations in 2 other H/ACA RNP complex genes, $N H P 2^{5}$ and NOP $10,{ }^{10}$ have also been linked to DC patients. Two subunits of the telomerase complex, telomerase reverse transcriptase (TERT) and the telomerase RNA component (TERC), together function in the de novo synthesis of telomere ends, ${ }^{11}$ and mutations in each component have been described in DC patients, although in general the phenotypes of these patients are relatively milder than those linked to $D K C 1$ mutations. ${ }^{12-14}$ Other mutations in genes coding for proteins that either protect telomere ends or assist in the trafficking of telomerase to Cajal bodies, TINF2 and TCAB1, respectively, have also been identified. ${ }^{15,16}$ One protein of unknown function,
C16orf57, has also recently been linked to DC, and these are the only patients that do not display shortened telomere lengths. ${ }^{17}$ Importantly, although most of the genotypes of DC identified to date have been single amino acid substitutions, it has recently been shown that a decrease in expression of $D K C 1$, in lieu of any gene mutations, is also linked to DC..$^{18}$

NOP10 is a short, 64-amino acid protein that shares approximately $60 \%$ homology with its yeast analog, Nop10p, originally identified by affinity purification of Garlp (also part of the H/ACA complex). ${ }^{19}$ The H/ACA complex, in addition to its role in telomere maintenance, also functions in guiding the pseudo-uridinylation of rRNAs, ribosome biogenesis, splicing of small nuclear RNAs, and select microRNA processing. ${ }^{20-22}$ Loss of mature $18 \mathrm{~S}$ rRNA results from $d k c 1$ hypomorphic mutations in mice, ${ }^{23}$ and the loss of snoRNA components required for normal 18S rRNA processing is evident in yeast cells lacking Nop10p. ${ }^{19}$ The homozygous R34W mutation in human NOP10 was identified in a large consanguineous family with a history of classic DC. ${ }^{10}$ This mutation was shown to result in shorter telomeres in DC-affected family members, although shortened telomeres were also identified in healthy heterozygous carriers of R34W. ${ }^{10}$ The homozygous R34W mutation was also shown to result in decreased levels of TERC in DC patients, and knockdown of NOP10 in a transient system was able to successfully recapitulate the lowered levels of TERC observed in DC patient cells. ${ }^{10}$ Taken together with the recent $D K C 1$ patient data, ${ }^{18}$ these results suggest that decreasing the expression of NOP10 in a model system is an efficient method for studying the mechanism of DC.

Although there is broad consensus that DC results from stem cell renewal failure, and incontrovertible evidence that telomeres play an important role, there remains a considerable amount of
Submitted April 29, 2011; accepted September 1, 2011. Prepublished online as Blood First Edition paper, September 14, 2011; DOI 10.1182/blood-2011-04351460 .

${ }^{*}$ T.C.P. and L.J.v.W. contributed equally to this study.
The online version of this article contains a data supplement.

The publication costs of this article were defrayed in part by page charge payment. Therefore, and solely to indicate this fact, this article is hereby marked "advertisement" in accordance with 18 USC section 1734.

(C) 2011 by The American Society of Hematology 
debate over the mechanisms. One area of contention is over the contribution of ribosome biogenesis defects in DC. An example of this is hypomorphic $d k c l$ mice that do not exhibit telomere shortening until the fourth generation, whereas significant rRNA defects are apparent in the first generation. ${ }^{23}$ However, other studies have been unable to detect differences in rRNA processing in immortalized DC patient cell lines. ${ }^{24}$ Alternately, it has been recently postulated that the failure of IRES-mediated translation of certain mRNAs, including that of the p53 tumor suppressor, occurs when cells are subject to $d k c 1$ knockdown. ${ }^{25-27}$ In contrast, other studies have demonstrated stabilization of p53 in mouse hepatocyte cells induced to delete $d k c l .{ }^{28}$

The 553 tumor suppressor is the most studied protein in biology today because the $p 53$ gene is mutated in the majority of human cancers and p53 protein is regarded as one of the most important defenses in protecting cells against damage. p53 is typically kept at low levels in normal cells through a physical interaction with the E3 ubiquitin ligase Mdm2, which targets p53 for proteasomal degradation. ${ }^{29}$ Stabilization of p53 occurs under a myriad of cellular stresses, including but not limited to DNA damage, oncogene presence, hypoxia, and rRNA synthesis inhibition. ${ }^{30}$ DNA damage stabilizes p53 through phosphorylation events that uncouple p53 from Mdm2, whereas the defective rRNA synthesis (using RNA polymerase inhibitor drugs, such as actinomycin D, for example) can result in the binding of ribosomal proteins (rps), including but not limited to L5, L11, and S7 to Mdm2 and subsequent p53 stabilization. ${ }^{31-33}$ Stabilized p53 directly upregulates the expression of genes that (depending on the level of cellular stress and DNA damage) will either arrest the cell cycle and activate DNA repair enzymes or initiate apoptosis. ${ }^{30}$

The mutant zebrafish line hi2578 was generated in a large-scale screen for genes required for embryonic development in the laboratory of Dr Nancy Hopkins. ${ }^{34}$ The hi2578 line carries a viral insertion in the first intron of the nop10 gene that results in a decrease of nop10 transcript that is lethal to homozygous embryos by 5 days post fertilization (dpf; described by submission to http://zfin.org and on the Hopkins laboratory website, http:// web.mit.edu/hopkins/index.html). Here we demonstrate with these mutants that nop10 loss results in a failure of $18 \mathrm{~S}$ rRNA to be properly processed, which in turn results in a collapse of the 40S small ribosomal subunit. Furthermore, we demonstrate that widespread p53-specific apoptosis is coupled to the increased binding of Mdm2 to the small ribosomal protein S7. This results in increased degradation of $\mathrm{rpS} 7$, but not of large ribosomal proteins. The nop10 mutant embryos also fail to form hematopoietic stem cells (HSCs), a phenotype that is rescued by introducing a loss-of-function $p 53$ background. Interestingly, the mutants display no telomere shortening by $4 \mathrm{dpf}$. Our results suggest that one mechanism of the cytopenia phenotype of DC resulting from loss of the H/ACA complex is driven by ribosome biogenesis defects, resulting in p53-mediated apoptosis in HSCs during early development, caused at least partly by the association of $\mathrm{rpS} 7$ with Mdm2.

\section{Methods}

\section{Fish maintenance}

Zebrafish were raised and embryos obtained through natural spawning as previously described ${ }^{35}$ in accordance with all Dutch regulations and guidelines. The hi2578 and hi1034b mutant lines were a generous gift from the laboratory of Dr Nancy Hopkins (Massachusetts Institute of Technology, Cambridge, MA).

\section{Imaging}

In situ and whole-mount images were obtained using a Zeiss Axioplan Stereomicroscope (Carl Zeiss) equipped with a Leica digital camera using $5 \times, 10 \times$, or $20 \times$ magnifications.

\section{Northern blot analysis}

For rRNA processing blots, total RNA was isolated from 5 embryos at $4 \mathrm{dpf}$ with Trizol (Invitrogen), run on a 1\% formaldehyde gel, and probed as previously described ${ }^{36}$ using prehybridization and hybridization solution (Clontech) at $65^{\circ} \mathrm{C}$ and $0.1 \%$ SDS/ $0.2 \times$ saline sodium citrate wash buffer also at $65^{\circ} \mathrm{C}$. For $\mathrm{p} 53$ blots, total RNA isolated from 20 embryos was probed with full-length p53 as previously described. ${ }^{37}$ Imaging of the blots was done using phosphor-imaging screens (Molecular Dynamics) followed by scanning using a Typhoon Scanner (GE Healthcare). Quantifications were performed using Quantity One 1D analysis software (Bio-Rad).

\section{In situ hybridizations}

In situ hybridizations were performed as previously described. ${ }^{38,39}$ The embryo genotypes were verified after in situ hybridization analysis in a PCR using primers MSL4 (5'-GCTAGCTTGCCAAACCTACAGGT), hi2578 forward (5'-CGTGAGAGTTCATCATGTTC), and hi2578 reverse (5'-CTTCAGTATGCTACACCACAGTG).

\section{TUNEL assay}

TUNEL assays were performed using a kit (Roche Diagnostics) according to the manufacturer's specifications.

\section{o-Dianisidine staining}

Embryos were anesthetized with Tricane at $36 \mathrm{hpf}$ and stained with $1 \mathrm{mg} / \mathrm{mL}$ o-dianisidine (Sigma-Aldrich) in staining buffer (40\% ethanol, $10 \mathrm{mM} \mathrm{NaAc}, 0.675 \% \mathrm{H}_{2} \mathrm{O}_{2}$ ) for 15 minutes in the dark.

\section{RT-PCR}

cDNA was constructed using the Cloned AMV First-Strand cDNA Synthesis Kit (Invitrogen) and RNA isolated using Trizol (Invitrogen) from 4-dpf embryos. Zebrafish nop 10 was amplified using primer pairs 5 '-AGTGGACCCCAGTGGTCAG-3' and 5'-GTCAGCAGGAGTCCGAATCT-3'. Zebrafish $\beta$ actin-2 was amplified using primer pairs 5'-GGACCTGTATGCCAACACTG-3' and 5'-TGATCTCCTTCTGCATCCTG-3'.

\section{Western blot analysis}

Embryos were subject to 25 Gy of $\gamma$-irradiation, mechanically de-yolked 6 hours later using a P200 pipette, lysed, and subjected to analysis as previously described using 5 embryos/sample. ${ }^{37}$ Cycloheximide (SigmaAldrich) was added to DMEM plus 10\% FCS (Invitrogen) at a concentration of $100 \mu \mathrm{g} / \mathrm{mL}$ to embryos that had first been treated with $5 \mathrm{mg} / \mathrm{mL}$ dispase (Sigma-Aldrich), 2.5\% trypsin (Invitrogen), 5\% DNAse RQ1 (Promega) in DMEM, plus 10\% FCS (Invitrogen) for 20 minutes at $30^{\circ} \mathrm{C}$ to obtain single-cell suspensions. The incubation of cycloheximide-treated cells was done in a $28^{\circ} \mathrm{C}$ incubator plus $5 \% \mathrm{CO}_{2}$. Antibodies used were ap53 (16H12 supernatant diluted 1:1 in blocking solution), ${ }^{37} \alpha \operatorname{rpS} 7$ (1:200; \#100834, Santa Cruz Biotechnology), arpL11 (1:200; \#25931, Santa Cruz Biotechnology), $\alpha \operatorname{rpL5}$ (1:200; \#103865 Santa Cruz Biotechnology), and aactin (1:1000; \#1616, Santa Cruz Biotechnology). Quantifications of Western blot bands were done using a GS-800 densitometer (Bio-Rad) and Quantity One software (Bio-Rad).

\section{Coimmunoprecipitation}

The 4-dpf embryos were de-yolked and lysed as for Western blotting, protein concentrations and volumes normalized to $1 \mathrm{mg}$ in $200 \mu \mathrm{L}$ lysis buffer, and incubated overnight at $4^{\circ} \mathrm{C}$ with either $2 \mu \mathrm{L} \alpha \mathrm{rpS} 7-\mathrm{IP}$ antibody or $2 \mu \mathrm{L}$ of preimmune serum (both kind gifts from Dr Carol Prives, previously described). ${ }^{33} \mathrm{~A}$ total of $50 \mu \mathrm{g}$ of lysate was removed from each 
A
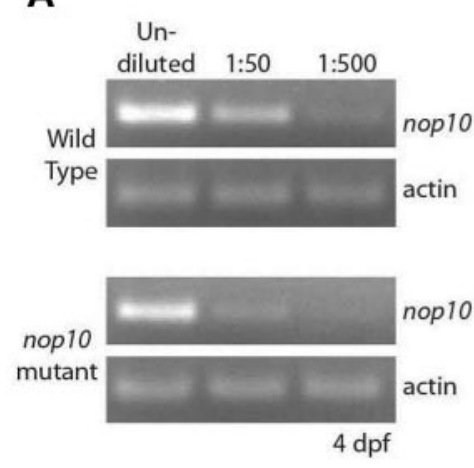

B

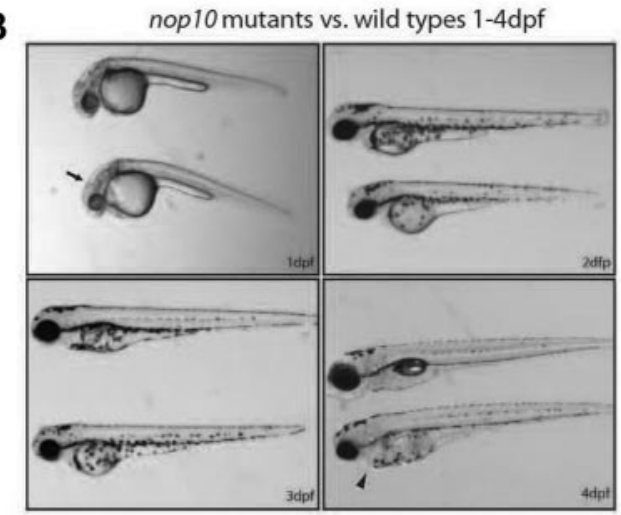

C
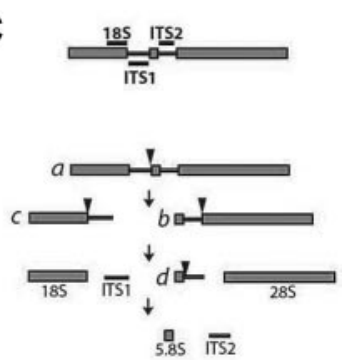

D

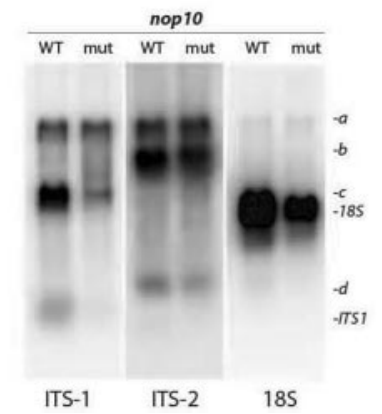

E

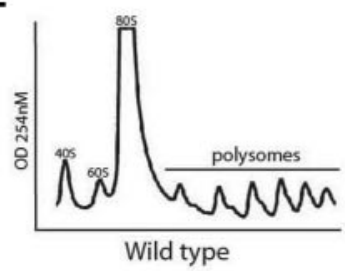

$\mathbf{F}$

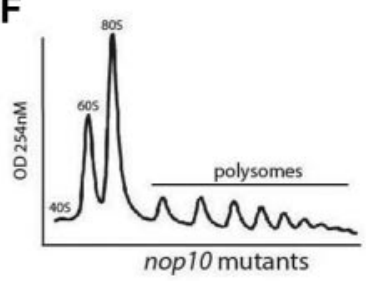

Figure 1. nop10 loss results in ribosome biogenesis defects affecting the small ribosomal subunit. (A) Semiquantitative PCR analysis on wild-type versus nop10 mutants at $4 \mathrm{dpf}$ using nop 10 or actin primers. (B) Gross morphology of the nop10 mutant compared with a wild-type sibling from 1 to 4 dpf. Arrow indicates dent in mid-hind brain barrier; and arrowhead, pericardial edema. (C) A contemporary schematic illustrating the major pathway of rRNA processing in zebrafish. Hybridization sites of ITS-1, ITS-2, and 18S probes are indicated on top. Arrowheads indicate major cleavage sites. (D) Northern blot analysis of total RNA isolated from nop10 mutants compared with wild-type siblings at $4 \mathrm{dpf}$ using probes against ITS-1, ITS-2, and 18S. (E-F) Polysome profiles of wild-type siblings (E) compared with nop10 mutants (F) at 4 dpf. The 40 , $60 \mathrm{~S}, 80 \mathrm{~S}$, and polysomal peaks are indicated.

sample before antibody additions for $5 \%$ input analysis. A total of $40 \mu \mathrm{L}$ of Protein A/G Plus agarose beads (Santa Cruz Biotechnology) was added and incubated for 2 hours at $4^{\circ} \mathrm{C}$ with gentle turning of the tubes. The agarose beads were spun down at $1500 \mathrm{~g}$ for 5 minutes and washed 3 times with ice-cold lysis buffer. After the final wash, the beads were resuspended in $20 \mu \mathrm{L}$ of $2 \times$ Laemmli buffer (Bio-Rad) plus $1 \mu \mathrm{L} \beta$-mercaptoethanol (Sigma-Aldrich), incubated for 5 minutes at $95^{\circ} \mathrm{C}$, and spun down at $1500 \mathrm{~g}$ for 5 minutes. Samples for $\alpha$ Mdm2 (\#55470; AnaSpec) blotting (including $5 \%$ input samples) were run on an $8 \%$ SDS-PAGE gel, while technical duplicate samples for $\alpha \mathrm{rpS} 7$ (\#135372; Santa Cruz Biotechnology) blotting were run on a $15 \%$ gel (including $5 \%$ input samples). Blotting was performed as described in "Western blot analysis," using dilutions of 1:500 for $\alpha \mathrm{Mdm} 2$ and 1:200 for $\alpha \mathrm{rpS} 7$.

\section{Polysomal profiling}

Fifty zebrafish embryos were homogenized with a Dounce tissue grinder (Wheaton) on ice in $500 \mu \mathrm{L}$ of polysome lysis buffer $(0.11 \mathrm{M}$ potassium acetate, $20 \mathrm{mM}$ magnesium acetate, 10mM HEPES, pH 7.6, $100 \mathrm{mM}$ potassium chloride, $10 \mathrm{mM}$ magnesium chloride, $0.1 \%$ NP-40, 2mM DTT, and $40 \mathrm{U} / \mathrm{mL}$ RNase inhibitor; Promega). Nuclei and debris were removed from the lysates by centrifuging at $1100 \mathrm{~g}$ for 10 minutes at $4^{\circ} \mathrm{C}$ in a tabletop centrifuge (Eppendorf $5415 \mathrm{R}$ ). Lysates were layered on $11 \mathrm{~mL}$ of a $17 \%$ to $50 \%$ sucrose gradient and centrifuged at $27000 \mathrm{~g}$ at $4^{\circ} \mathrm{C}$ for 2 hours in an SW40 Ti rotor (Beckman) and a Kontron T-1080 ultracentrifuge. Samples were displaced in a fractionator (Brandell) using a $60 \%$ sucrose solution, and the RNA content read by a UA-6 absorbance reader (Teledyne ISCO) at $280 \mathrm{UV}$.

\section{Real-time PCR analysis}

RNA was isolated from each individual peak using Trizol LS (Invitrogen). RNA was used to create cDNA using Cloned-AMV First Strand cDNA
Synthesis Kit (Invitrogen) according to the manufacturer's protocol, using an Oligo(dT) primer. Gene expression was analyzed using a MyiQ Single Color Real-Time PCR Detection System on a Bio-Rad iCycler. A total of $1 \mu \mathrm{L}$ cDNA was used in combination with FastStart High Fidelity PCR reagents (Roche Diagnostics) and $1 \mu \mathrm{L} 3.75 \times$ SYBR Green (SigmaAldrich) in a volume of $25 \mu \mathrm{L}$ total, except for the no-template control (neg). Primers for zebrafish $\mathrm{p} 53$ used were $5^{\prime}$-TTAAGTGATGTGGTGCCTGCCT-3' and 5'-AGCTTCTTTCCCTGTTTGGGCT- $3^{\prime}$. Primers for zebrafish ßactin-2 used were 5'-GGACCTGTATGCCAACACTG-3' and $5^{\prime}$-TGATCTCCTTCTGCATCCTG-3'. All reactions were performed in triplicate for 45 cycles. Data output was obtained using MyiQ Version 1.0+ software and analyzed with Microsoft Office Excel 2007. The average $C_{t}$ was determined, and $\Delta \mathrm{C}_{\mathrm{t}}$ was calculated by subtracting $\mathrm{C}_{\mathrm{t}}$ target from $\mathrm{C}_{\mathrm{t}}$-neg. Next, the relative amount of p53 compared with the total amount of RNA (represented by actin) was calculated $\left(\Delta \mathrm{C}_{\mathrm{t}}[\mathrm{p} 53] \Delta \mathrm{C}_{\mathrm{t}}[\right.$ actin] $\left.]\right)$. To visualize the difference between the wild-type and mutant samples, the relative amounts of p53 mRNA were calculated as a ratio of mutant/wildtype, wherein the amount in the wild-type was set to 1 . These were performed with biologic duplicates.

\section{Telomere length assay}

Telomere assay was done using the Telomere PNA Kit/FITC for Flow Cytometry (Dako). Control cells used were a human lymphoblast cell line obtained from Dr Hanna Gazda. Single-cell suspensions of 4 dpf zebrafish embryos were obtained by incubating approximately 200 embryos at $30^{\circ} \mathrm{C}$ for 1 hour in an Eppendorf Thermoshaker at $500 \mathrm{rpm}$ in $750 \mu \mathrm{L}$ of $1 \times \mathrm{PBS}$ with $0.25 \mathrm{mg} / \mathrm{mL}$ dispase I (Sigma-Aldrich), $0.125 \%$ trypsin (Invitrogen), 50 U RQ1 RNase-Free DNase (Promega), and 10\% FCS. Cells were then pulled through a $0.6-\mathrm{mm}$ needle and filtered through a $35-\mu \mathrm{m}$ nylon mesh cell strainer cap (Falcon). 
A
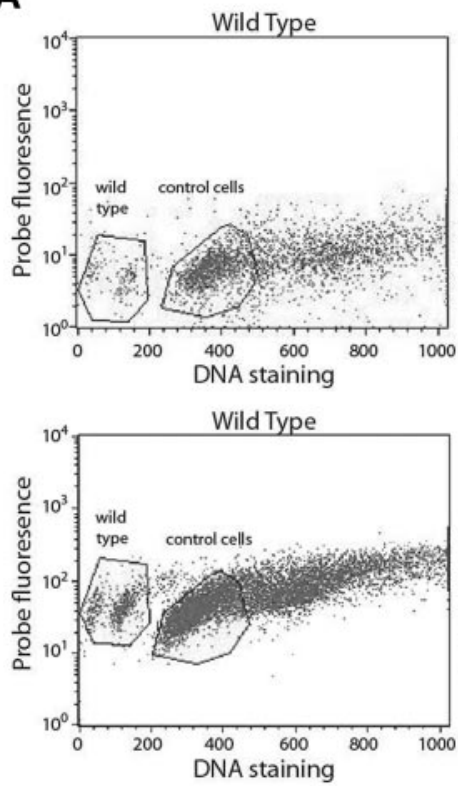
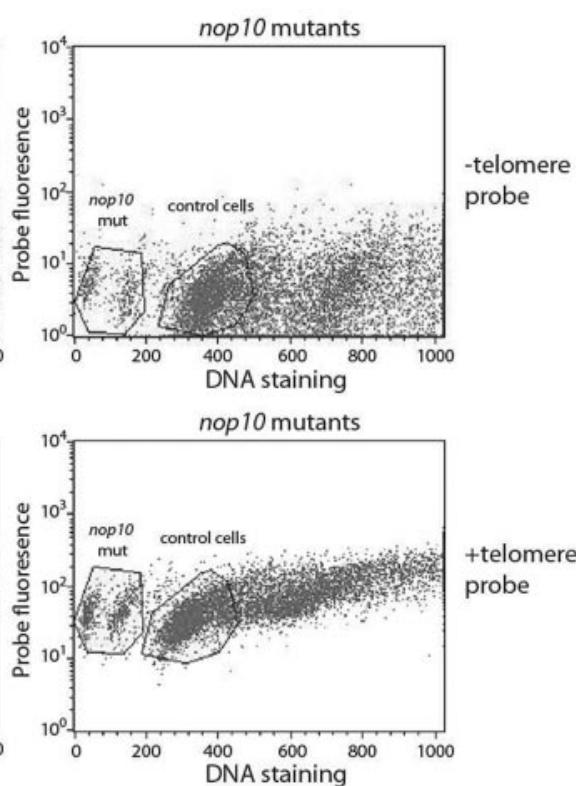

B

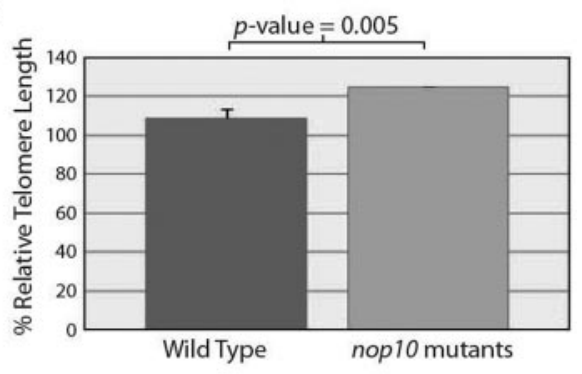

Figure 2. Loss of nop10 results in no detectable telomere shortening. (A) No evidence of a shift difference is detectable in wild-type versus nop 10 mutant cells at 4 dpf on hybridization of a telomere-specific probe. Gated cells represent those in $\mathrm{G}_{0 / 1}$. (B) Quantification of panel A, calculating the percentage relative telomere length compared with control cells.

\section{Results}

\section{A viral insertion in the hi2578 zebrafish line results in impaired $18 \mathrm{~S}$ rRNA processing and $40 \mathrm{~S}$ ribosomal subunit collapse}

A viral insertion in the first intron of the nop 10 gene in the hi2578 zebrafish line results in the decreased expression of nop10 in homozygous embryos by $4 \mathrm{dpf}$ (Figure 1A). Homozygous embryos are distinguishable at $1 \mathrm{dpf}$ by a slight dent in the mid-hindbrain barrier, and by 4 dpf have a smaller head and eyes, an underdeveloped liver and gut, and frequent pericardial edema (Figure 1B). Their swim bladders do not inflate, they exhibit a phlegmatic touch response, and most die by $5 \mathrm{dpf}$. The heterozygous nop 10 embryos develop into normal adults and to date have not been shown to have a predisposition to malignancy or other gross phenotypes.

Because it has been previously demonstrated in yeast that Nop10p loss results in impairment of $18 \mathrm{~S}$ rRNA pseudouridinylation and processing, ${ }^{19}$ we performed northern blot analysis to determine whether similar effects are evident in zebrafish embryos. Figure 1C shows a basic schematic of rRNA processing in zebrafish embryos derived from the results in our laboratory as well as those previously reported. ${ }^{36}$ Using probes designed to bind to the internally transcribed sequence 1 (ITS1), internally transcribed sequence 2 (ITS2), or 18S rRNA, we were able to observe an impairment of $18 \mathrm{~S}$ rRNA processing in nop 10 mutants (Figure 1D). A significant loss of the precursor rRNA strand that ultimately makes up the $18 \mathrm{~S}$ strand is visible in the lanes probed with ITS1; moreover, a significant decrease in the total amount of $18 \mathrm{~S}$ rRNA is evident in lanes probed with 18S. In contrast, lanes probed with ITS2 appear to be relatively similar between wild-types and mutants, suggesting that there is little impairment of $28 \mathrm{~S}$ or $5.8 \mathrm{~S}$ rRNA processing in nop 10 mutants. Polysome profiling reveals an almost complete loss of the $40 \mathrm{~S}$ peak that represents the small ribosome subunit in the nop10 mutants compared with wild-types
(Figure 1E-F), which is consistent with an 18S rRNA processing impairment.

\section{Telomere shortening does not occur on nop10 loss}

To determine whether the loss of nop10 could result in shorter telomeres in our mutants, we measured the relative telomere lengths of 4-dpf embryonic cells in $\mathrm{G}_{0} / \mathrm{G}_{1}$ with or without a fluorescent telomere sequence-specific probe compared with control cells (a normal human tissue culture cell line). Both control cells and zebrafish embryonic cells show an upward shift in fluorescent intensity when incubated with the telomere probe; however, there was no difference detected between the shift of the wild-type cells compared with nop10 mutant cells (Figure 2), which would have indicated a difference in telomere length.

\section{Loss of nop 10 increases p53}

To evaluate the consequences of the loss of small ribosome subunit formation, we examined the status of the p53 tumor suppressor. Typically, the induction of DNA damage in zebrafish embryos by $\gamma$-irradiation results in p53 stabilization. ${ }^{37}$ This is observed by Western blotting with a zebrafish p53-specific antibody in $4 \mathrm{dpf}$ wild-type embryos treated with 25 Gy of $\gamma$-irradiation after 6 hours (Figure 3A). nop 10 mutant embryos at $4 \mathrm{dpf}$ in the absence of DNA damage also reveal p53 stabilization, a result that is consistent with rRNA synthesis deficiencies. ${ }^{30}$ No further increase of p53 stabilization is evident in nop 10 mutants on $\gamma$-irradiation. Expression of the $\Delta 113$ p53 isoform is evident in both the mutants and irradiated wild-types (Figure 3A). Transcription of $p 53$ is also increased significantly in nop 10 mutants, shown by northern blot analysis (Figure 3B-C). Moreover, using real-time PCR analysis of mRNA isolated from polysomal fractions, we were able to demonstrate that this increase in cellular p53 mRNA in nop 10 mutants is coupled to an increase in the amount of p53 mRNA that is loaded onto polysomes (Figure 3D). Injection of a translation-blocking p53 morpholino (MO) into embryos at the one cell stage followed 
A

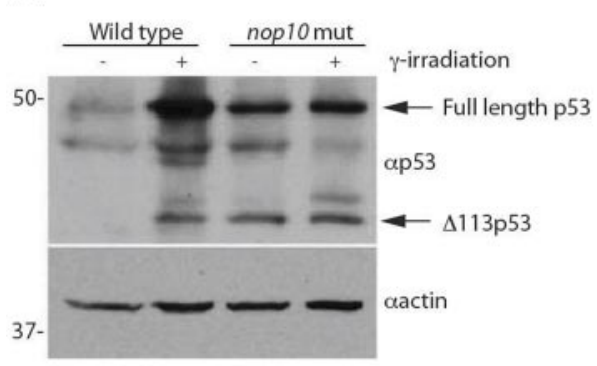

B

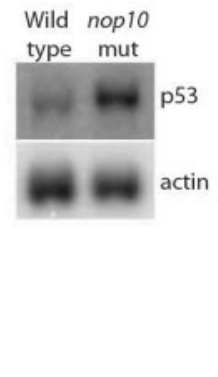

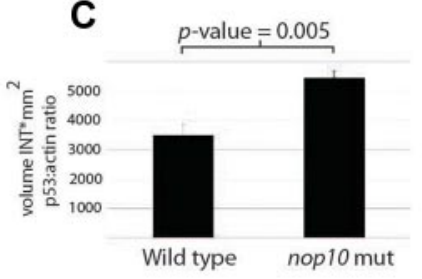

E

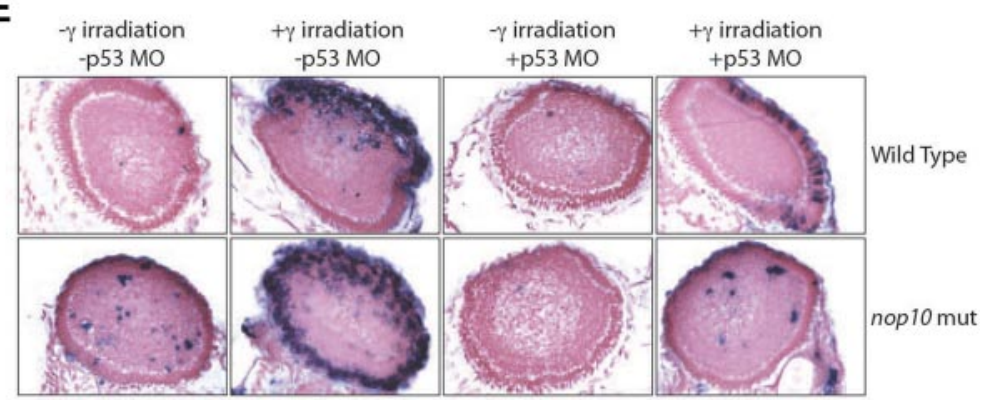

Figure 3. nop10 loss results in p53-dependent apoptosis. (A) Western blot analysis of p53 protein stabilization in 4-dpf embryos either untreated or treated with 25 Gy $\gamma$-irradiation and incubated for 6 hours. (B) Northern blot analysis of p53 mRNA levels in nop 10 mutant embryos compared with wild-type siblings at 4 dpf. (C) Quantification of 3 independent $p 53$ Northern blots comparing the level of $p 53$ :actin mRNA by densitometer analysis. (D) Real-time PCR analysis indicating the relative ratios of $p 53$ :actin mRNA in individual fractions isolated from polysome profiles of wild-type or nop 10 mutants at 4 dpf. Fractions 2 to 4 represent the monosomal portion of the profile, and fractions 5 to 10 represent the polysomal portion. (E) TUNEL assay (focusing on the zebrafish eye) indicating cells undergoing apoptosis in embryos untreated, treated with 25 Gy $\gamma$-irradiation and incubated for 6 hours, injected at the 1-cell stage with a p53-MO, or both. Images were obtained using a Nikon Eclipse E600 microscope with $40 \times$ Nikon Plan Fluor, 0.75 NA dry objective. A Leica DFC 500 camera was used with Leica Application Suite Version 3.6.0 software.

by TUNEL analysis at $4 \mathrm{dpf}$ reveals a significant reduction in the number of TUNEL-positive cells on histologic slides of p53 MO-injected nop10 embryos (Figure 3E). These results indicate that the rRNA synthesis defect of the nop10 mutants initiates cellular apoptosis in a p53-dependent manner and that a decrease of p53 mRNA translation does not occur.

\section{nop10 loss results in Mdm2 binding to and degradation of rpS7}

We surmised that nop10 loss would result in a pool of free small rps, unable to incorporate into a ribosome subunit because of the loss of $18 \mathrm{~S}$ rRNA, now available to bind other proteins, such as the E3 ubiquitin ligase Mdm2. rpS7 is one small subunit rp that has been shown in vitro to be able to bind to MDM2 on actinomycin D treatment. ${ }^{33,40}$ Coimmunoprecipitation of $\mathrm{rpS} 7$ and blotting with a zebrafish specific Mdm2 antibody reveal an increased amount of $\mathrm{Mdm} 2$ binding to rpS7 in nop10 mutants compared with wild-types (Figure 4A). It has furthermore been demonstrated in vitro that the rpS7-MDM2 association results in the E3 ubiquitin ligase activity of MDM2 promoting the degradation of $\operatorname{rpS} 7 .{ }^{33}$ To test this, we subjected zebrafish embryo cells to cycloheximide treatment and then determined the expression levels of $\mathrm{rpS7}$, rpL5, and rpL11. Figure 4B-C illustrates that, by 4 hours after cycloheximide exposure, the expression of $\mathrm{rpS} 7$ in nop 10 mutant cells is substantially decreased compared with $\mathrm{rpS} 7$ in wild-type cells. This is in contrast to an absent or mild reduction of expression of large ribosomal subunit proteins $\mathrm{L} 5$ and L11, respectively. To assess whether rpS7 is the only small rp binding Mdm2 and causing p53 stabilization, we crossed the hi1034b line (carrying a viral insertion in the rpS7 gene) $)^{41}$ with the hi2578 line to create double nop10;rpS7 mutants. These double mutants do not show a reduction of p53 stabilization compared with the nop10 mutant alone at the same age (Figure 4D-E), suggesting that rpS7 is most likely not the only protein binding $\mathrm{Mdm} 2$ and decoupling it from $\mathrm{p} 53$. (These blots were performed at $2 \mathrm{dpf}$ because of the earlier lethality of the double mutants). This is not surprising given the other rps known to bind Mdm2, including rpS3. ${ }^{42}$ These data strongly suggest that the collapse of the small ribosomal subunit in nop 10 embryos results in increased binding of small rps with Mdm2 followed by the subsequent degradation of $\mathrm{rpS} 7$

\section{Loss of nop10 results in a p53-dependent loss of HSC formation}

One of the hallmarks of DC is cytopenia, which may be because of a loss of HSC formation in early development. To determine the effect of nop10 loss on HSC development, we first performed whole-mount hemoglobin staining with o-dianisidine. Figure 5A demonstrates that at $36 \mathrm{hpf}$ hemoglobin-expressing RBCs are clearly visible in the yolk and heart of wild-type embryos in contrast to very few visible in nop 10 mutants. This suggests that the nop10 mutants, similar to DC patients, experience erythrocyte loss. We next performed in situ hybridizations to measure the levels of BE1-globin and rag-1 in 36-hpf and 4-dpf embryos, respectively. The $\beta E 1$-globin gene is known in zebrafish embryos to be up-regulated in erythroid cells during early stages of primitive hematopoiesis. ${ }^{43}$ Figure 5B illustrates a significant decrease in staining of $\beta E 1$-globin in nop 10 mutants compared with wild-type embryos at $36 \mathrm{hpf}$, suggesting a link between nop 10 loss and an impairment of primitive hematopoiesis. Figure 5B additionally shows a complete absence of rag- 1 transcripts in nop10 mutant embryos at $4 \mathrm{dpf}$, indicating a loss of differentiated thymic T cells that is also consistent with the DC anemia phenotype. To ascertain whether this blood cell loss was the result of deregulated p53 stabilization, we introduced a homozygous loss-of-function p53 $3^{M 214 K / M 214 K}$ allele ${ }^{44}$ to the nop10 mutant background. At $1 \mathrm{dpf}$, 
A
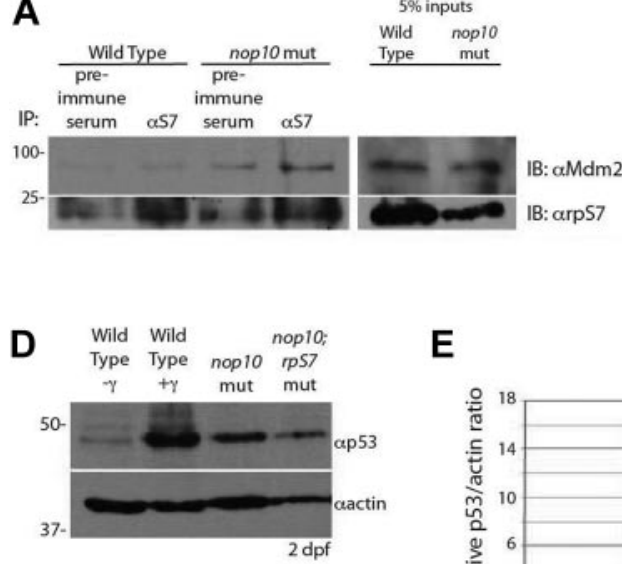

E
B

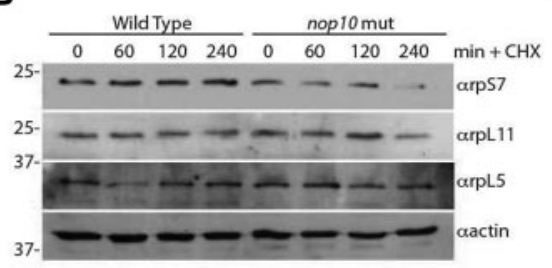

C

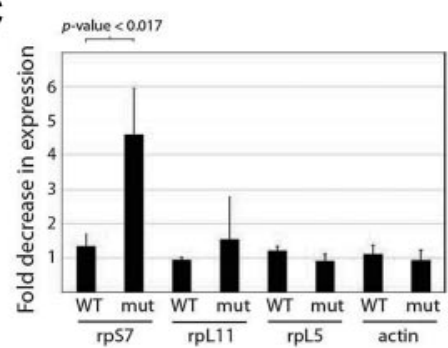

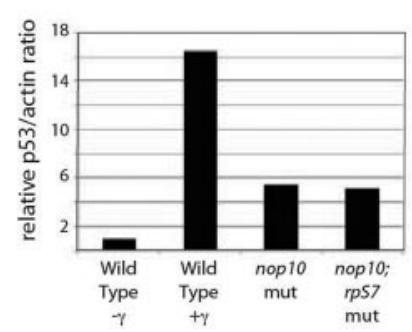

Figure 4. nop10 loss causes rpS7 binding to Mdm2 and increased degradation of rpS7. (A; left) Immunoprecipitation of embryo lysates at 4 dpf with preimmune serum or $\alpha \mathrm{rpS} 7$ followed by blotting with $\alpha \mathrm{Mdm} 2$ (top) or $\alpha \mathrm{rpS} 7$ (bottom). (Right) A total of $50 \mu \mathrm{g} \mathrm{(5 \% )} \mathrm{of} \mathrm{total} \mathrm{lysate} \mathrm{used} \mathrm{for} \mathrm{immunoprecipitations} \mathrm{blotted} \mathrm{with} \mathrm{either} \alpha \mathrm{rpS} 7$ or $\alpha \mathrm{Mdm} 2$ (note: these samples are on the same blots as the immunoprecipitations but are displayed separately because of different exposure requirements). (B) Western blot analysis of levels of rpS7, rpL11, rpL5, and actin in wild-type and nop10 mutant embryos treated with cycloheximide for 0 to 4 hours. (C) Quantification of 3 independent experiments indicating the protein with the largest fold decrease of expression in 4 hours after cycloheximide treatment is rpS7 in nop 10 mutant embryos. (D) Western blot analysis of 2 dpf wild-type embryos untreated or treated with 25 Gy $\gamma$-irradiation, nop10 mutants, or nop10;rpS7 mutants. (E) Densitometer quantification of expression levels in panel D comparing relative $\mathrm{p53}$ /actin ratios, setting the wild-type $\gamma$-ratio to 1 .

unlike the nop10 mutants, the nop10;p53 $3^{M 214 K / M 214 K}$ mutants were indistinguishable from clutch siblings (data not shown). However, by $2 \mathrm{dpf}$, the gross nop 10 mutant phenotype was evident; and by 4 to $5 \mathrm{dpf}$, the nop 10;p53 $3^{M 214 K / M 214 K}$ mutants looked very similar to the nop10 mutants alone (supplemental Figure 1, available on the Blood Web site; see the Supplemental Materials link at the top of the online article). O-Dianisidine staining of nop 10;p53 $3^{M 214 K / M 214 K}$ mutants revealed a complete rescue of hemoglobin-producing RBCs compared with nop 10 mutants, illustrated in representative clutch samples in Figure 5C. Western blot analysis of the nop10; $p 53^{M 214 K / M 214 K}$ mutants in Figure 5D compared with $p 53^{M 214 K / M 214 K}$ mutants alone indicates hyperstabilization of p53 protein in the double mutants with or without $\gamma$-irradiation and also loss of the $\Delta 113$ p53 protein (consistent with recent evidence that wild-type p53 is required for induction of $\Delta 113$ p53). ${ }^{45}$ Next, we tested levels of $c-m y b$ and runx-1 transcripts that are expressed in emerging definitive hematopoietic stem and progenitor cells by in situ hybridization. In wild-type zebrafish embryos at $36 \mathrm{hpf}$, these markers are evident in cells within the dorsal aorta (Figure 5E). In contrast, very little expression of $c-m y b$ or runx- 1 is detected in nop10 mutants at $36 \mathrm{hpf}$, suggesting a loss of definitive HSC formation. Substantial rescue of runx-1 and $c-m y b$ expression is also revealed in the nop 10;p53 $3^{M 214 K / M 214 K}$ mutants compared with nop10 mutants alone (Figure 5E-F). Taken together, these data suggest that the loss of HSCs observed in nop 10 mutants is p53-dependent.

\section{Discussion}

The impaired proliferative and renewal capacity of stem cells is a generally accepted mechanism underlying the phenotypes of DC. This could occur in 2 ways: one would be an initial reduction of total stem cell numbers during early development, and another would be the gradual loss of stem cell function over time because of critically short telomeres inducing senescence. Our zebrafish model of DC supports the previous hypomorphic Dkcl murine model, ${ }^{23}$ suggesting that mutations affecting the H/ACA RNP complex in early development result in phenotypes because of ribosome biogenesis defects before the onset of telomere shortening.

The ribosome biogenesis defects in our zebrafish model drive p53-dependent apoptosis of HSCs (and perhaps other stem cell types) and suggest similar defects may play a role in the DC cytopenia phenotype through a reduction of initial stem cell numbers. After development is complete, the shortening of telomeres over time and senescence then probably plays a second role in stem cell failure, probably including a further decrease of blood cell formation. This model may explain why DC patients carrying $d k c l$ mutations tend to exhibit some of the most deleterious phenotypes, as both an initial stem cell reduction and gradual stem cell failure are presumably affecting these patients. It is also consistent with recent studies that mice with homozygous mutations in either TERT or TERC do not show any evidence of p53 activation under basal conditions, ${ }^{46}$ or any overt phenotypes for several generations, ${ }^{47}$ whereas first-generation mice with hypomorphic $d k c l$ mutations exhibit both bone marrow and skin phenotypes reminiscent of DC. ${ }^{23}$ Taken together, these data argue against the idea that H/ACA complex gene mutations, such as $d k c 1$ and nop 10 in DC, elicit stem cell failure strictly through telomere shortening and, instead, suggest that p53 stabilization in early development reduces the total number of stem cells because of small rps binding Mdm2. It seems unlikely that mutations in TERT or TERC would result in a similar phenomenon, having no known role in rRNA processing, although these mutations may drive stem cell failure later through their well-established role in telomere maintenance and the links between critically short telomeres, senescence, and apoptosis. ${ }^{48}$ The data also suggest that perhaps DC linked to mutations in C16orf57, which do not result in telomere shortening, may be instead the result predominantly of p53 deregulation in early development.

Although it is interesting that the introduction of the $p 53^{M 214 K /}$ $M 214 K$ alleles to the nop 10 mutants does not seem to result in a significant rescue beyond very early development, this is most 
A

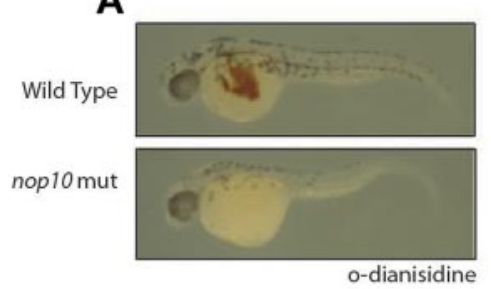

D

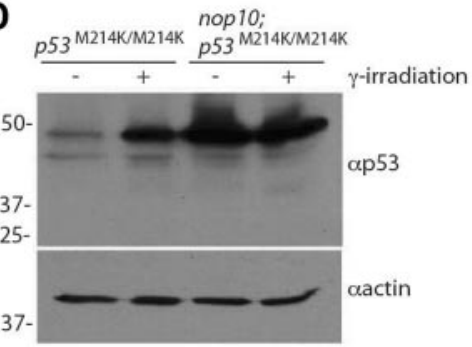

B
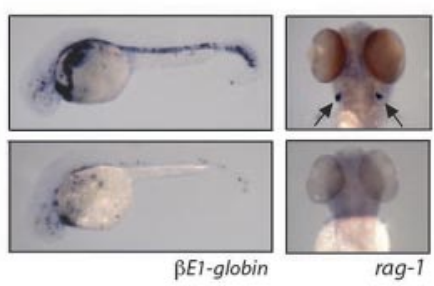

C
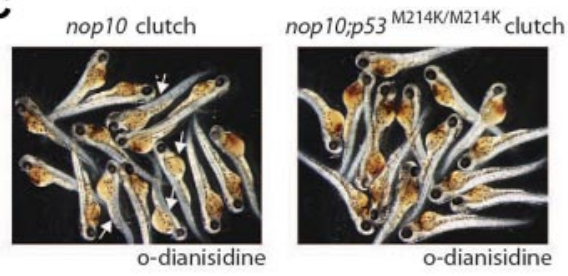

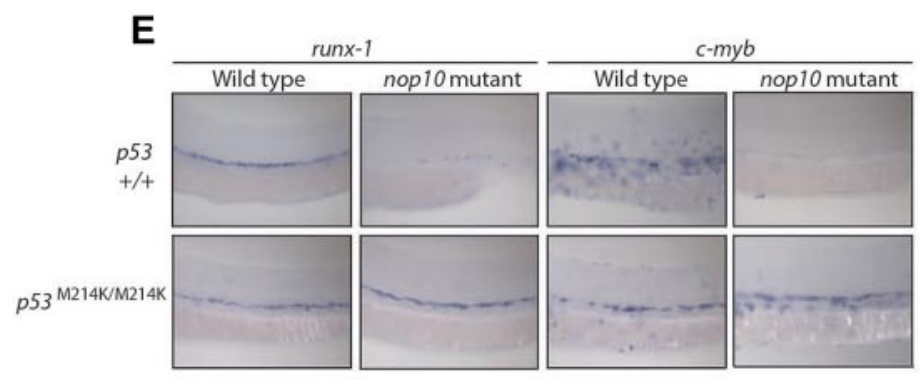

$\mathbf{F}$

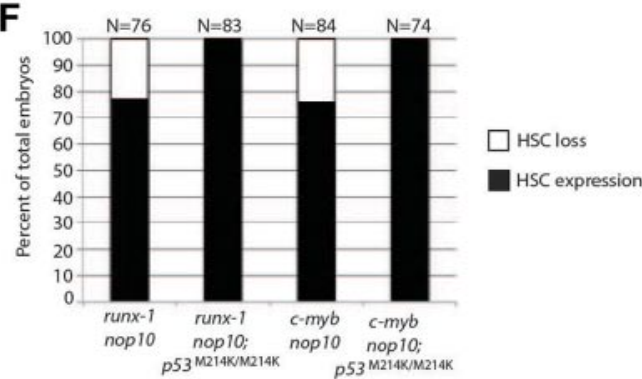

Figure 5. nop10 loss results in p53-dependent defects in HSC formation. (A) O-Dianisidine staining of whole RBCs at 36 hpf in nop10 mutant embryos or wild-type siblings. (B) In situ hybridization analysis of $\beta E 1$-globin (36 hpf) or rag-1 (4 dpf) mRNA levels. (C) O-Dianisidine staining in a sampling from 36 -hpf clutches of either nop10 mutants (left) and wild-type siblings (arrows indicate mutants) or nop10;p53 ${ }^{M 214 K / M 214 K}$ mutants and p53 ${ }^{M 214 K / M 214 K}$ siblings (right). (D) Western blot analysis of p53 stabilization in nop 10; $553^{M 214 K / M 214 K}$ embryos compared with $p 53^{M 214 K / M 214 K}$ embryos in the presence or absence of 25 Gy $\gamma$-irradiation. (E) In situ hybridization analysis of runx-1 mRNA (left) or c-myb mRNA (right) in 36-hpf nop 10 mutant embryos compared with clutch siblings either in a $p 53$ wild-type background (top) or $p 53^{M 214 K / M 214 K}$ mutant background (bottom). Embryos were mounted in methylcellulose and images were obtained using a Zeiss Axioplan microscope with a $10 \times$ Zeiss Neofluor, 0.3 NA dry objective. A Leica DFC 480 camera was used with Leica Application Suite Version 3.5.0 software. (F) Quantification of in situ hybridization results showing percentages of the HSC-loss phenotype in total clutches of embryos.

probably the result of the induction of other methods of programmed cell death. p53-independent mechanisms of cell death can occur in other ribosome biogenesis mutants; for example, the lethality of rpL35 loss in zebrafish embryos is not rescued by the $p 53^{M 214 K / M 214 K}$ alleles, although there is a slight amelioration of the mutant phenotype in very early development similar to what we observe with the nop10;p53 $3^{M 214 K / M 214 K}$ mutants (A. Amsterdam and A.W.M., unpublished results, January 2008). Nevertheless, it is clear that, within that timeframe of early development (within $36 \mathrm{hpf}$ ), the slight rescue effect of $p 53^{M 214 K / M 214 K}$ is enough for HSC development to proceed in nop 10 mutants.

We present in this work a vertebrate model of nop 10 loss and a novel zebrafish model of DC. Our results with this model bring together how impairment of rRNA processing by nop10 loss can result in the cytopenia phenotype common in DC through the interaction of $\mathrm{rpS} 7$ with $\mathrm{Mdm} 2$ and stabilization of p53 in HSCs. Although it remains to be determined whether this phenomenon may be attributed to all stem cell types, our zebrafish model suggests the existence of 2 mechanisms of stem cell failure in DC patients depending on the type of mutation. Dysfunction of the H/ACA complex in our zebrafish model results in rp-mediated p53 stabilization in early development, whereas other DC mutations in genes involved solely in telomere maintenance more probably cause stem cell proliferation defects through the shortening of telomeres over time.

\section{Acknowledgments}

The authors thank J. Korving and H. Begthel of the histology laboratory and S. Holwerda for excellent technical assistance; the animal facility caretakers of the Hubrecht Institute; the group of S. Schulte-Merker for the in situ hybridization probes; and R. Ketting, S. Schulte-Merker, and D. Guardavaccaro for helpful discussions and critical readings of the manuscript.

This work was supported by the Koninklijke Nederlandse Akademie van Wetenschappen (KNAW) and the Hubrecht Institute (A.W.M.).

\section{Authorship}

Contribution: A.W.M. conceived of and designed the experiments and wrote the manuscript, and all authors performed the experiments and collected and analyzed data.

Conflict-of-interest disclosure: The authors declare no competing financial interests.

The current affiliation for A.B. is Department of Rheumatology, Erasmus Medical Centre, Rotterdam, The Netherlands.

Correspondence: Alyson W. MacInnes, Hubrecht Institute, KNAW and Universitair Medisch Centrum Utrecht, Uppsalalaan 8, Utrecht, 3584 CT, The Netherlands; e-mail: a.macinnes@ hubrecht.eu. 
From bloodjournal.hematologylibrary.org at Universiteitsbibliotheek Utrecht on December 20, 2011. For personal

BLOOD, 17 NOVEMBER 2011• VOLUME 118, NUMBER 20

use only.

THE EFFECTS OF Nop10 LOSS IN ZEBRAFISH

\section{References}

1. Tamary H, Nishri D, Yacobovich J, et al. Frequency and natural history of inherited bone marrow failure syndromes: the Israeli Inherited Bone Marrow Failure Registry. Haematologica. 2010; 95(8):1300-1307.

2. Kirwan M, Dokal I. Dyskeratosis congenita, stem cells and telomeres. Biochim Biophys Acta. 2009; 1792(4):371-379.

3. Knight S, Vulliamy T, Copplestone A, Gluckman E, Mason P, Dokal I. Dyskeratosis Congenita (DC) Registry: identification of new features of DC. Br J Haematol. 1998;103(4):990-996.

4. Jacobs P, Saxe N, Gordon W, Nelson M. Dyskeratosis congenita: haematologic, cytogenetic, and dermatologic studies. Scand J Haematol. 1984;32(5):461-468.

5. Vulliamy T, Beswick R, Kirwan M, et al. Mutations in the telomerase component NHP2 cause the premature ageing syndrome dyskeratosis congenita. Proc Natl Acad Sci U S A. 2008;105(23): 8073-8078.

6. Basel-Vanagaite L, Dokal I, Tamary H, et al. Expanding the clinical phenotype of autosomal dominant dyskeratosis congenita caused by TERT mutations. Haematologica. 2008;93(6): 943-944.

7. Alter BP, Giri N, Savage SA, Rosenberg PS. Cancer in dyskeratosis congenita. Blood. 2009; 113(26):6549-6557.

8. Vulliamy TJ, Marrone A, Knight SW, Walne A, Mason PJ, Dokal I. Mutations in dyskeratosis congenita: their impact on telomere length and the diversity of clinical presentation. Blood. 2006; 107(7):2680-2685.

9. Knight SW, Heiss NS, Vulliamy TJ, et al. Unexplained aplastic anaemia, immunodeficiency, and cerebellar hypoplasia (Hoyeraal-Hreidarsson syndrome) due to mutations in the dyskeratosis congenita gene, DKC1. Br J Haematol. 1999; 107(2):335-339.

10. Walne AJ, Vulliamy T, Marrone A, et al. Genetic heterogeneity in autosomal recessive dyskeratosis congenita with one subtype due to mutations in the telomerase-associated protein NOP10. Hum Mol Genet. 2007;16(13):1619-1629.

11. Cech TR. Beginning to understand the end of the chromosome. Cell. 2004;116(2):273-279.

12. Vulliamy T, Marrone A, Goldman F, et al. The RNA component of telomerase is mutated in autosomal dominant dyskeratosis congenita. Nature. 2001;413(6854):432-435.

13. Armanios M, Chen JL, Chang YP, et al. Haploinsufficiency of telomerase reverse transcriptase leads to anticipation in autosomal dominant dyskeratosis congenita. Proc Natl Acad Sci U S A. 2005;102(44):15960-15964.

14. Vulliamy TJ, Walne A, Baskaradas A, Mason PJ, Marrone A, Dokal I. Mutations in the reverse transcriptase component of telomerase (TERT) in patients with bone marrow failure. Blood Cells Mol Dis. 2005;34(3):257-263.

15. Savage SA, Giri N, Baerlocher GM, Orr N, Lansdorp PM, Alter BP. TINF2, a component of the shelterin telomere protection complex, is mu tated in dyskeratosis congenita. Am J Hum Genet. 2008;82(2):501-509.

16. Zhong F, Savage SA, Shkreli M, et al. Disruption of telomerase trafficking by TCAB1 mutation causes dyskeratosis congenita. Genes Dev. 2011;25(1):11-16.

17. Walne AJ, Vulliamy T, Beswick R, Kirwan M, Dokal I. Mutations in C16orf57 and normal-length telomeres unify a subset of patients with dyskeratosis congenita, poikiloderma with neutropenia and Rothmund-Thomson syndrome. Hum Mol Genet. 2010;19(22):4453-4461.

18. Parry EM, Alder JK, Lee SS, et al. Decreased dyskerin levels as a mechanism of telomere shortening in X-linked dyskeratosis congenita. J Med Genet. 2011;48(5):327-333.

19. Henras A, Henry Y, Bousquet-Antonelli $C$, NoaillacDepeyre J, Gelugne JP, Caizergues-Ferrer M Nhp2p and Nop10p are essential for the function of H/ACA snoRNPs. EMBO J. 1998;17(23):7078 7090.

20. Matera AG, Terns RM, Terns MP. Non-coding RNAs: lessons from the small nuclear and small nucleolar RNAs. Nat Rev Mol Cell Biol. 2007;8(3): 209-220.

21. Kiss $T$, Fayet E, Jady BE, Richard P, Weber M Biogenesis and intranuclear trafficking of human box C/D and H/ACA RNPs. Cold Spring Harb Symp Quant Biol. 2006;71:407-417.

22. Reichow SL, Hamma T, Ferre-D'Amare AR, Varani G. The structure and function of small nucleolar ribonucleoproteins. Nucleic Acids Res. 2007;35(5):1452-1464

23. Ruggero D, Grisendi S, Piazza F, et al. Dyskeratosis congenita and cancer in mice deficient in ribosomal RNA modification. Science. 2003; 299(5604):259-262.

24. Montanaro L, Chilla A, Trere D, et al. Increased mortality rate and not impaired ribosomal biogenesis is responsible for proliferative defect in dyskeratosis congenita cell lines. J Invest Dermatol. 2002;118(1):193-198.

25. Yoon A, Peng G, Brandenburger Y, et al. Impaired control of IRES-mediated translation in X-linked dyskeratosis congenita. Science. 2006; 312(5775):902-906.

26. Montanaro L, Calienni M, Bertoni S, et al. Novel dyskerin-mediated mechanism of p53 inactivation through defective mRNA translation. Cancer Res. 2010;70(11):4767-4777.

27. Bellodi C, Kopmar N, Ruggero D. Deregulation of oncogene-induced senescence and p53 translational control in X-linked dyskeratosis congenita. EMBO J. 2010;29(11):1865-1876.

28. Ge J, Rudnick DA, He J, et al. Dyskerin ablation in mouse liver inhibits rRNA processing and cell division. Mol Cell Biol. 2010;30(2):413-422.

29. Momand J, Zambetti GP, Olson DC, George D, Levine AJ. The mdm-2 oncogene product forms a complex with the p53 protein and inhibits p53mediated transactivation. Cell. 1992;69(7):12371245.

30. Horn HF, Vousden KH. Coping with stress: multiple ways to activate p53. Oncogene. 2007;26(9) 1306-1316.

31. Dai MS, Lu H. Inhibition of MDM2-mediated p53 ubiquitination and degradation by ribosomal protein L5. J Biol Chem. 2004;279(43):44475-44482.

32. Lohrum MA, Ludwig RL, Kubbutat MH, Hanlon M, Vousden KH. Regulation of HDM2 activity by the ribosomal protein L11. Cancer Cell. 2003;3(6): 577-587.
33. Zhu Y, Poyurovsky MV, Li Y, et al. Ribosomal protein $\mathrm{S} 7$ is both a regulator and a substrate of MDM2. Mol Cell. 2009;35(3):316-326.

34. Amsterdam A, Burgess S, Golling G, et al. A large-scale insertional mutagenesis screen in zebrafish. Genes Dev. 1999;13(20):2713-2724.

35. Westerfield M. The Zebrafish Book: A Guide for the Laboratory Use of Zebrafish (Danio rerio). 4th ed. Eugene, OR: University of Oregon Press: 2000.

36. Azuma M, Toyama R, Laver E, Dawid IB. Perturbation of rRNA synthesis in the bap28 mutation leads to apoptosis mediated by p53 in the zebrafish central nervous system. J Biol Chem. 2006;281(19):13309-13316.

37. Maclnnes AW, Amsterdam A, Whittaker CA, Hopkins N, Lees JA. Loss of p53 synthesis in zebrafish tumors with ribosomal protein gene mutations. Proc Natl Acad Sci U S A. 2008; 105(30):10408-10413.

38. Diks SH, Bink RJ, van de Water S, et al. The novel gene asb11: a regulator of the size of the neural progenitor compartment. J Cell Biol. 2006; 174(4):581-592.

39. Burns CE, Traver D, Mayhall E, Shepard JL, Zon LI. Hematopoietic stem cell fate is established by the Notch-Runx pathway. Genes Dev. 2005;19(19):2331-2342.

40. Chen D, Zhang Z, Li M, et al. Ribosomal protein $\mathrm{S} 7$ as a novel modulator of p53-MDM2 interaction: binding to MDM2, stabilization of p53 protein, and activation of p53 function. Oncogene. 2007;26(35):5029-5037.

41. Amsterdam A, Sadler KC, Lai K, et al. Many ribosomal protein genes are cancer genes in zebrafish. PLoS Biol. 2004;2(5):E139.

42. Yadavilli S, Mayo LD, Higgins M, Lain S, Hegde V, Deutsch WA. Ribosomal protein S3: a multi-functional protein that interacts with both $\mathrm{p} 53$ and MDM2 through its KH domain. DNA Repair. 2009; 8(10):1215-1224.

43. Brownlie A, Hersey C, Oates AC, et al. Characterization of embryonic globin genes of the zebrafish. Dev Biol. 2003;255(1):48-61.

44. Berghmans S, Murphey RD, Wienholds E, et al. tp53 mutant zebrafish develop malignant peripheral nerve sheath tumors. Proc Natl Acad Sci U S A. 2005;102(2):407-412.

45. Guo L, Chua J, Vijayakumar D, et al. Detection of the 113 p53 protein isoform: a p53-induced protein that feeds back on the p53 pathway to modulate the $\mathrm{p} 53$ response in zebrafish. Cell Cycle. 2010;9(10):1998-2007.

46. Vidal-Cardenas SL, Greider CW. Comparing effects of mTR and mTERT deletion on gene expression and DNA damage response: a critical examination of telomere length maintenance-independent roles of telomerase. Nucleic Acids Res. 2010;38(1):60-71.

47. Blasco MA, Lee HW, Hande MP, et al. Telomere shortening and tumor formation by mouse cells lacking telomerase RNA. Cell. 1997;91(1):25-34.

48. Saretzki G, Sitte N, Merkel U, Wurm RE, von Zglinicki T. Telomere shortening triggers a p53-dependent cell cycle arrest via accumulation of G-rich single stranded DNA fragments. Oncogene. 1999;18(37):5148-5158. 